Altai State University

Acta Biologica Gibirica

Journal of Biology

Founded in 2015 www.asu.ru

ISSN 2412-1908

Acta Biologica Sibirica, 2017, 3(3), 117-121

UDC 595.754

\title{
Comparative analysis of distribution the species of the Heteroptera of Tuva in width-zonal gradient
}

\author{
S.V. Kuzhuget \\ Tuvinian Institute for Exploration of Natural Resources SB RAS, Kyzyl, Russia \\ E-mail: sedenmaa@mail.ru
}

In the article, the features of the distribution of hemiptera along the width-zonal gradient are considered, which is reflected in the depression - Turan-Uyuk, Central-Tuva and Uvs-nuur, located from the north to the south. The ways of adaptation of hemiptera to the arid climate of the Ubs-nuur depression are singled out.

Key words: terrestrial; Heteroptera; widtn-zonal gradient; depression; Tuva

\section{Сравнительный анализ распределения наземных Полужесткокрылых (Insecta, Heteroptera) Тувы по широтно-зональному градиенту}

\author{
С.В. Кужугет \\ Тувинский институт комплексного освоения природных ресурсов СО РАН, Кызыл, Россия. \\ E-mail: sedenmaa@mail.ru
}

В статье рассмотрены особенности распределения наземных полужесткокрылых по широтно-зональному градиенту, который отражается в котловинах - Турано-Уюкской, Центрально-Тувинской и Убсунурской, расположенных с севера на юг. Выделены пути приспособления клопов к аридному климату Убсунурской котловины.

Ключевые слова: вид; наземные полужесткокрылые; широтно-зональный градиент; котловина; Тува

\section{Введение}

Животные, как и растения, служат показателем изменчивости степных экосистем по широтно-зональному градиенту (Мордкович, 2014). В Туве же закон широтной зональности отчетливо отражен в расположенных с севера на юг котловинах - Турано-Уюкской, Центрально-Тувинской и Убсунурской. В них, климатические условия меняются с севера на юг: годовое количество осадков, среднемноголетние температуры (Рис. 1). 


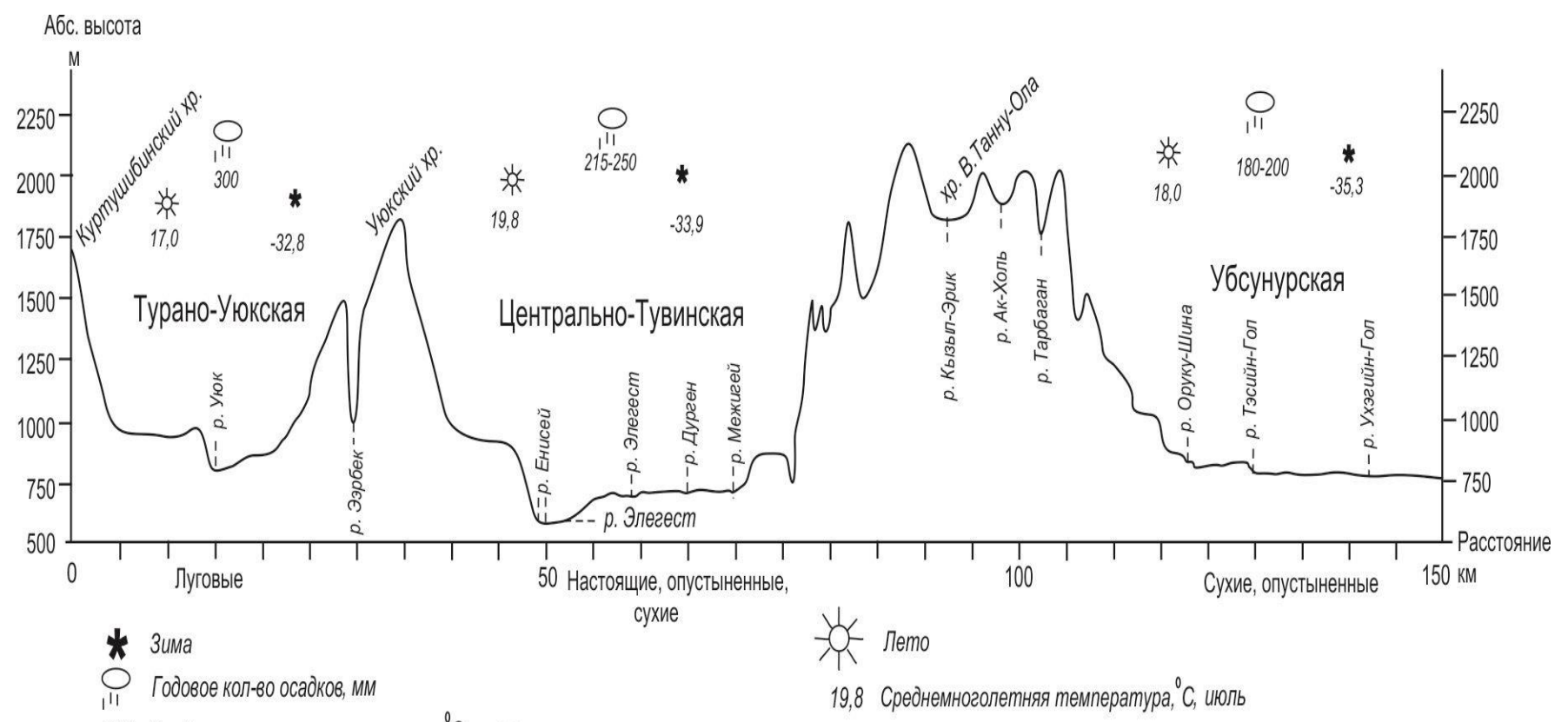

Масштаб: вертикальный 1:25000

\section{Рис. 1. Геоморфологический разрез трех сравниваемых котловин с гидротермическими показателями} (ГМС г. Кызыла, среднемноголетние исследования с 1960 по 2010 гг.)

(автор разреза инженер-картограф Н.Н. Григорович)

Из-за обрамления Тувы с запада и севера горными системами, влагоносные воздушные массы приходят в Центрально-Тувинскую котловину сильно обедненные влагой, большая часть которой остается на наветренных склонах Алтая и Саян. Хребет Танну-Ола задерживает остатки влаги северо-западных воздушных течений, вследствии чего Убсу-Нурская котловина получает вдвое меньшее количество осадков, чем другие котловины.

Большое влияние на Турано-Уюкскую котловину оказывают гумидные горы Южной Сибири, на Убсу-Нурскую - область опустыненных степей и пустынь бессточных котловин Северной Монголии. Соответственно, при продвижении с севера на юг изменяется состав степной растительности, усиливается ксерофитизация. Так, для Турано-Уюкской котловины характерны луговые степи, для Центрально-Тувинской - сухие, настоящие крупно - и мелкодерновинные, а также опустыненные, а в Убсу-Нурской - сухие и опустыненные степи становятся преобладающими (Самбуу, 2014).

В данной работе мы ставили перед собой следующие задачи: 1) показать как распределяются наземные полужесткокрылые в соответствии с параметрами широтно-зонального градиента; 2) выделить ключевые механизмы приспособления клопов к аридным условиям Убсу-Нурской котловины.

\section{Материалы и методы исследования}

Материалом исследований послужили сборы автора, проводившиеся с 2009 по 2017 гг. в данных котловинах Тувы. Наземные полужесткокрылые были собраны в основном с помощью методов кошения энтомологическим сачком и ручным сбором насекомых с растений, с подстилки. На южном и северном берегах оз. Торе-Холь в 2016 г. насекомые ловились на свет с помощью УФ лампы Osram (250Вт).

Собранные насекомые замаривались (этилацетатом), раскладывались на ватные матрасики, затем монтировались на энтомологические булавки и этикетировались (Кужугет, 2016г)

В целом объем изученного материала составляет более 10 тыс. экземпляров.

\section{Результаты и их обсуждение}

Самая богатая фауна наземных полужесткокрылых наблюдается в Центрально-Тувинской котловине - 323 вида. На втором месте в видовом разнообразии стоит Убсу-Нурская котловина - 205 видов. Самое меньшее количество видов наземных полужесткокрылых наблюдается в Турано-Уюкской котловине - 114 видов.

Большое видовое разнообразие наземных полужесткокрылых в Центрально-Тувинской котловине можно объяснить тем, что данная котловина самая большая котловина в Туве, которая охватывает различные биотопы. Это злаковые и полынно-злаковые степи на каштановых почвах сменяющиеся опустыненными степями и нанофитоновыми полупустынями на светло-каштановых почвах (Стебаев, 1968). В Убсунурской котловине преобладают сухие степи и полупустыни, поэтому количество видов наземных клопов в ней меньше. ТураноУюская котловина, по сравнению с другими котловинами, самая маленькая, и в данный момент это единственный аргумент, который может объяснить имеющее количество видов в ней. Поскольку преобладающие в Турано- 
Уюской котловине луговые степи должны были включать, согласно широтно-зональному градиенту, большее количество видов наземных клопов. Но, пока наши результаты показывают совершенно иное.

Таким образом, общее видовое разнообразие наземных полужесткокрылых не уменьшается в связи с последовательным изменением растительного покрова степных экосистем с севера на юг.

Зональная смена биотопов в рассматриваемых котловинах является, как уже отмечалось, экологическим следствием закона географической зональности и объясняется возрастанием по мере продвижения на юг количества тепла, получаемой земной поверхностью. Резкое возрастание эффективной радиации по мере продвижения на юг ставит расселяющийся здесь вид в условия избытка тепла. Этот избыток тепла на сухом юге (в нашем случае Убсу-Нурская котловина) может быть устранен путем перехода в более увлажненные и тенистые стации: высокая почвенная влажность способствует охлаждению через усиленное испарение, а тень умеряет прогревающий эффект южного солнца. С другой стороны, недостаток тепла и избыток влаги компенсируется переходом на более сухие и теплые стации (Бей-Биенко, 2008). Поэтому, чтобы понять, отличаются ли части котловин видовым разнообразием наземных полужесткокрылых провели следующие сравнения. Количество видов в восточной части Центрально-Тувинской котловины (модельная точка - р. Каа-Хем, нижнее течение, пойменный лес, взяты 4 укоса: в 1979 г., в 2014 г., в 2015 г., в 2016 г.) соспоставили с количеством видов в западной части Центрально-Тувинской котловины (модельная точка - р. Чаа-Холь, пойменный лес, взяты также 4 укоса: 2 укоса в 2009 г., 1 в 2012 г. и 1 в 2013 г.). В итоге мы получили результат, который показывает, что биоразнообразие наземных полужесткокрылых в восточной части котловины больше - собрано 63 вида, чем в западной части котловины - здесь клопов насчитывается 39 видов. Причина меньшего количества видов в западной части котловины состоит в том, что она находятся в «дождевой тени» гор, и поэтому наиболее аридна. Восточные части котловин Алтае-Саянской системы, обращенные навстречу западному переносу влажных воздушных масс, получают значительно больше осадков, чем центральные и западные (Петров, 19526).

Следующий параметр широтно-зонального градиента - это увлажнение. Оно определяет формирование экологических групп в котловинах как у растений, так и у животных.

Распределение экологических групп наземных полужесткокрылых по нашим исследованиям, как видно из диаграммы (Рисунок 2), в зависимости от степени увлажнения биотопа во всех котловинах неравномерное преобладают мезофилы.

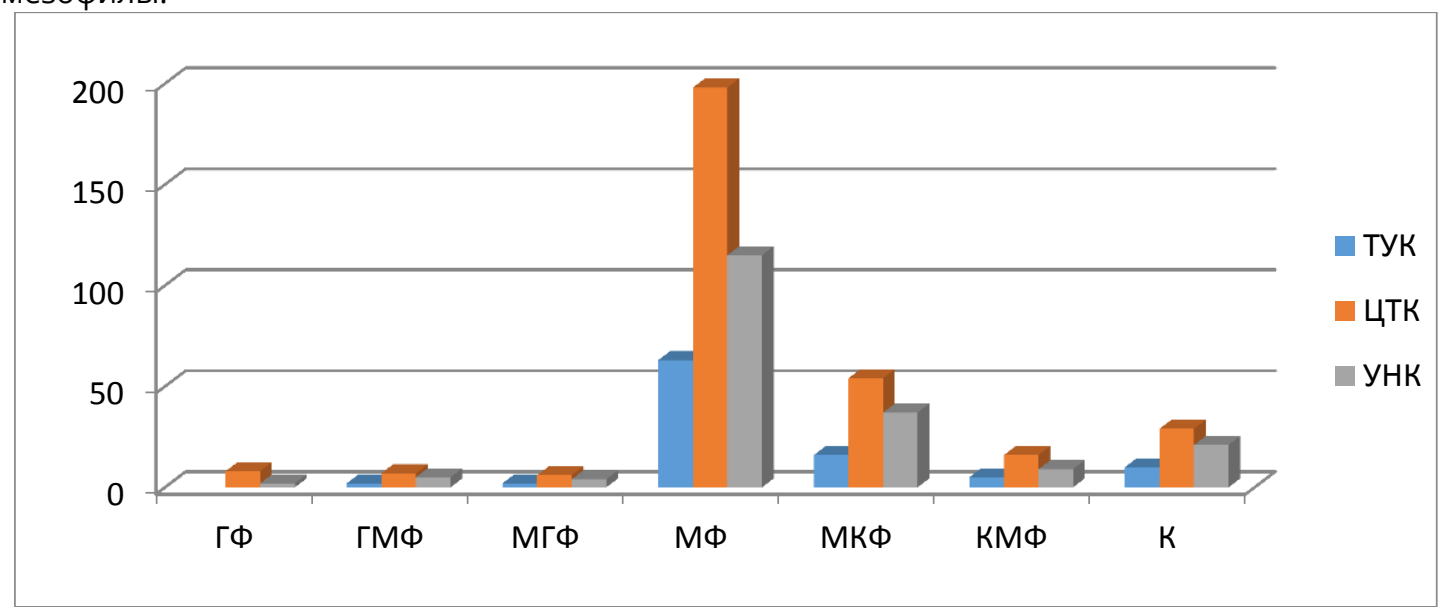

Рис. 2. Распределение наземных полужесткокрылых в трех котловинах в зависимости от степени увлажненности биотопа.

Сокращения: ГФ - гигрофилы; ГМФ - гигро-мезофилы; МГФ - мезо-гигрофилы; МФ - мезофилы; МКФ - мезоксерофилы; КМФ - ксеро-мезофилы; К - ксерофилы.

Меньшее количество мезо-ксерофилов, ксеро-мезофилов и ксерофилов отмечено в Турано-Уюкской котловине, чем в Убсу-Нурской. В Убсу-Нурской котловине больше ксерофильных видов. Они занимают полынные и злаково-разнотравные, опустыненные степи, а также сухие и солончаковатые луга: Psallopsis neglecta Konst., Paranysius fraterculus fraterculus Horv., Phimodera reuteri Kir., Antheminia lindbergi Tam., Tarisa salsae Kerzh.

В Центрально-Тувинской котловине все численные показатели выше, чем в двух других котловинах. В ней представлены все группы, в том числе гигрофилы, гигро-мезофилы, а также ксеро-мезофилы и ксерофилы. Это можно объяснить тем, что Центрально-Тувинская котловина включает в себя основные типы степей, имеющихся в двух других котловинах. Вследствие того, что она находится на стыке двух крупных фаунистических комплексов (монгольского с юга и сибирского с севера), представляя тем самым и полностью изолированный горными хребтами участок (Флинт, Головкин, 1961), на котором формируется своя фауна. По данным Гаджиева и др. (2002), в котловине распространены в основном настоящие мелко- и крупнодерновинные степи, но встречаются деградированные варианты настояших степей и опустынные степи. Луговые степи появляются обычно в лесостепном поясе.

Все вышесказанное показывает, что распределение экологических групп наземных полужесткокрылых в котловинах зависит от степени увлажненности биотопов в них. 
Почему же все-таки в Убсунурской котловине количество видов наземных клопов всего лишь в 1,5 раза меньше, чем в Центрально-Тувинской? Попробуем ответить на этот вопрос путем анализа путей приспособления клопов к аридному климату.

Клопы, как и все насекомые-фитофаги, большую часть воды необходимую для обмена веществ и роста, получают из пищи. При дефиците влаги в организме насекомые выбирают для питания наиболее сочные корма, если это возможно (Яхонтов, 1964а). Такие кормовые растения в большей степени, благодаря климатическим условиям, имеются в Турано-Уюкской и Центрально-Тувинской котловинах. В Убсу-Нурской котловине обитают виды, которые приспособились питаться растениями, произрастающими в сухих и опустыненных степях. В ТураноУюкской котловине произрастают мезофильные растения, а в Убсу-Нурской котловине высококалорийные ксерофильные (типчак, змеевка, полынь холодная), которые считаются в сельском хозяйстве нажировочнокалорийными кормами. Ведь наряду с другими проспособлениями, существенную роль в сохранении влаги играет метаболическая вода. Она образуется при окислении различных органических веществ, особенно жиров. Метаболизм может быть единственным источником воды для некоторых обитателей полупустынь (Чернышев, 1996). В указанных нами растениях содержатся эфирные масла, которые являются жидкими жирами растительного происхождения. Например, в полыни холодной в лабораторных условиях смогли добыть от 0,07-0,27\% эфирного масла (Королюк, Ткачев, 2009).

При жажде насекомые могут компенсировать недостаток воды, поедая любые влажные субстраты. Насекомое не страдает от низкой влажности, если имеет возможность в любое время находить воду для питья (Чернышев, 1996). Это напрямую относится к растительноядным клопам. Клопы прокалывают ткани растения и поглощают их сок. Ксерофильные растения Убсу-Нурской котловины характеризуются узкими листьями с наружной толстой стенкой, наличием водоносной ткани, увеличенной водопроводящей системой и т.д., а суккулентам котловины характерны большие запасы воды, крупные клетки, слабое развитие проводящей системы и т.д. Максимальное содержание воды в листьях у степных ксерофитов изменяется от 50,7 до 93,5\% в зависимости от экологической приуроченности вида. Минимумы находятся в переделах 18,3-83,8\%. Особенно низкое содержание воды у дерновинных злаков, причем мелкодерновинные виды (Festuca valesiaca, Koeleria cristata) более обводненны по сравнению с крупнодерновинными (Stipa glareosa, S. pennata, Helictotrichon desertorum). Высокий уровень содержания воды в листьях степных суккулентов (Orostachys spinosa, Allium senescens и др.), мезофитов, ксеромезофитов и мезоксерофитов. Повышенные максимальные значения отмечены и для ряда типичных ксерофитов (Косһіa prostrata, Artemisia frigida и др.) (Горшкова, Зверева, 1988).

\section{Выводы}

1. Общее видовое разнообразие наземных полужесткокрылых с изменением растительного покрова степных экосистем котловин, по нашим исследованиям, не уменьшается. На противоположных бортах ЦентральноТувинской котловины видовое разнообразие наземных полужесткокрылых различное.

2. Центрально-Тувинская котловина является сосредоточением основных типов биотопов региона, поэтому в ней имеются все выделенные нами экологические группы наземных клопов.

3. Одно из главных приспособлений наземных клопов к аридному климату Убсунурской котловины являются извлечение ими воды, включая метаболической, из растений.

\section{References}

Bei-Bienko, G.Ya. (2008). Total entomology. St. Petersberg: «Prospect of Science» (In Russian). Gadjiev, I.M. (2002). Steppes of Inner Asia. Novosibirsk: SB RAS Publisher (In Russian).

Gorshkova, A.A. (1988). Ecology of the steppe plants of Tuva. Novosibirsk: Science (In Russian).

Korolyuk, E.A. (2009). Chemical composition of the essential oil from two wormwood species Artemisia frigida and Artemisia argyrophylla. Himija Rastitel'nogo Syr'ja, 4, 63-72 (In Russian). Retrieved from http://www.chem.asu.ru/chemwood/volume13/2009 04/0904 063.html

Kuzhuget, S.V. (2016g). The first information of the Heteroptera with Kaa-Khem mountain taiga district. Molodezhnyy nauchnyy vestnik, 12, 294-299 (In Russian). Retrieved from http: http://www.mnvnauka.ru/2016/12/Kuzhuget.pdf

Mordkovich, V. G. (2014). Steppe ecosystems. Novosibirsk: Academic publishing «Geo» (In Russian).

Petrov, B.F. (1952b). Soils of Altai-Sayan area. Annals of Dokuchaev Soil Institute AN SSSR, 35, 274 (In Russian).

Sambuu, A.D. (2014). Succession of plant communities in grasslands of Tuva: diss. ... dokt. biol. nauk: Novosibirsk (In Russian).

Stebaev, I.V. (1968). Zhivotnoye naseleniye pochv v beslessnykh biogeotsenozakh Altaye-Sayanskoy gornoy strany. In I.V. Stebaev (Eds.) The animal population chestnut and associated soils of Tuva and the southern part of Khakassia (pp. 7-78). Novosibirsk (In Russian).

Flint, V. Ye. (1961). The role of the ridge Tannu-Ola as a zoogeographical barrier and some problems of the origin of the Tuva steppe fauna. Zoological journal, XL (4), 556-566 (In Russian).

Chernyshev, V.B. (1996). Ecology of insects. Moscow: Mosk. Gos. Univ. (In Russian).

Yakhontov, V.V. (1964a). Ecology of insects. Moscow: Vysshaya Shkola (In Russian). 


\section{Citation:}

Kuzhuget, S.V. (2017). Comparative analysis of distribution the species of the Heteroptera of Tuva in width-zonal gradient. Acta Biologica Sibirica, 3 (3), 117-121

Submitted: 17.06.2016. Accepted: 11.08.2017

cross ref $\underline{\text { http://dx.doi.org/10.14258/abs.v3i3.3623 }}$ 